Of mercury and man

\section{Roy Harrison}

The Biogeochemistry of Mercury in the Environment. Edited by J.O. Nriagu. Pp.696. (Elsevier/North-Holland: Amsterdam, Oxford and New York, 1979.) $\$ 136.50$, Dfl. 280 .

THERE are few toxic substances with a history as long as that of mercury. The metal has been known and used for at least 3,500 years and still finds wide application today. There are documented instances of inorganic mercury poisoning dating back 500 years, and alkylmercury poisoning has been known for over 100 years. Yet mercury still provides surprises. Although the first cases of Minamata disease occurred in 1953, it was not until 1959 that alkylmercury poisoning was identified as the cause with any degree of certainty. Until that time, although occupational alkylmercury poisoning was known, the possibility of poisoning of the population by environmental exposure, in this case by consumption of fish which had absorbed alkylmercury from the effluent of a local chemical works, had not been suspected. It was not known that fish could concentrate alkylmercury from water, nor was it discovered until later that alkylation of inorganic mercury in aquatic sediments was possible.

Minamata and other incidents of mercury poisoning have stimulated more interest in mercury as a pollutant than in any other toxic agent with the possible exception of lead. Biogeochemistry, a new term to me, apparently embraces "the chemical behaviour and biological effects of mercury in the biosphere, geosphere and hydrosphere"'. In Nriagu's own words, it provides "the logical conceptual framework for looking holistically at the mercury cycle and the human impact upon it". These are grand ideas and to a large measure the book lives up to them. The coverage is extremely broad, including the production, uses and control of mercury, the environmental chemistry and biological effects of the metal in terms of occupational and environmental human exposure, and the effects on aquatic and terrestrial organisms. It includes detailed analyses of the outbreaks of organomercury poisoning at Minamata and Niigata in Japan (both due to consumption of contaminated fish) and in Iraq (due to the consumption of grain seed treated with mercurial fungicides).

The book contains 24 chapters, each written by specialists in a particular area. The result is quite impressive; there is a wealth of information which should satisfy most workers in this field, with relatively little overlap between contributions. Each chapter contains a large bibliography which is in most instances fairly up to date (references up to 1978 are included). As with much review material nowadays there is rarely any attempt at critical analysis, some chapters being little more than a listing of relevant work. That criticism aside, this book represents a valuable contribution for which many workers in this broad transdisciplinary field will be grateful.

Roy Harrison is a Lecturer in the Department of Environmental Sciences, University of Lancaster, UK.

\section{Keeping up in physics}

\section{W. Cochran}

A Perspective of Physics. Volume 3. Introduction by Sir Harrie Massey. Pp. 360. (Gordon and Breach: New York and London, 1979.) \$35.50.

IN 1695 delegates from the four Scottish Universities met as a Commission "to consider methods of instruction in philosophy"'. Their comments on draft reports covering various parts of the subject have been preserved, and we read for instance that "One part of the delegates are of opinion that Newton's hypothesis of the ebbing and flowing of the sea should be insert, or a reason given why it is not; and the other part think that there is no need to make any mention of it. The author gives this reason why he omitted it - because neither he nor any he has conversed with on the subject do so fully understand what Newton does write thereon as they can make it intelligible to young students". Any university teacher of physics who smiles at this in 1980 should do so wryly, for we have by no means solved by specialization that problem of keeping up to date with the advances made in our subject.

Volume 3 of A Perspective of Physics contains a selection of the articles which appeared in Comments on Modern Physics during 1978. This series appears in five sections, Nuclear and Particle Physics, Solid State Physics, Astrophysics, Atomic and Molecular Physics, and Plasma Physics. In 1978 about 100 short review articles appeared under one or other of these headings, and of these 29 are reproduced in the volume under review. The emphasis is on brevity; a typical article is $3000-4000$ words in length, with $20-30$ references. Topics range from "Charge Density Maps in Chemisorption" to "New Quarks and Old Ones Too", and Sir Harrie Massey is remarkably successful in putting the articles into perspective in his introduction. I must admit, however, that while I shall continue to read Comments on Solid State Physics as it appears, personally I find most other reviews in this series too terse and too specialist-directed when compared with those in, for example, Physics Today. We are better placed than our predecessors were three centuries ago, but there will never be an easy solution to the problem of understanding advances in physics.

W. Cochran is Professor of Natural Philosophy at the University of Edinburgh, UK.

\section{A vitamin D encyclopaedia}

\section{D.R. Fraser}

Vitamin D. The Calcium Homeostatic Steroid Hormone. By A.W. Norman. Pp.496. (Academic: New York and London, 1979.) \$48, £27.

KNOWLEDGE about vitamin D, we are told, falls into eras. There was the era of ignorance before 1920 , then the era of vitamin D chemistry and nutrition, followed by the 15-20-year era of vitamin D metabolism. We are now it seems in the era of vitamin D reviews, with recent books entitled Vitamin $D$ being produced by D.E.M. Lawson (Academic: New York and London, 1978), H.F. DeLuca (Springer: Heidelberg and New York, 1979) and this one by A.W. Norman, plus a myriad of review articles throughout the biological literature. Truly the subject is well publicized.

One must admire the energy and enthusiasm resulting in this latest account. The work aims and succeeds at being comprehensive. There are detailed descriptions of the chemistry, metabolism and function of vitamin $D$, with chapters reviewing the historical development of the topic and the medical relevance of the new knowledge. All this is supported by an extensive bibliography, the dates in which indicate a minimum delay in the publication process. It is an admirable book of reference on all aspects of the biology of vitamin D.

On the other hand it is also the vitamin D gospel very much according to Norman, and hence tends to be a catalogue of the notable achievements of the author and his colleagues. But in a curious way an opportunity has been missed here to give a lead in unravelling the complexities of vitamin D function. Rarely does the author allow his own insight to throw new light on this problem. Yet the mysteries of the mechanism of action of vitamin D are now more amen- 